\title{
Prevalence and causes of preoperative anaemia in elective major surgery patients
}

Frank S Hong ${ }^{1}$, Nicole Sieradzki ${ }^{2}$, Claire Pollock ${ }^{2}$, Faye Nasra ${ }^{2}$, Allison $\mathrm{Mo}^{3}$, Abbey Willcox ${ }^{3}$, Leonid Churilov $^{4,5}$, Wai Khoon $\mathrm{Ho}^{1}$ and Carole Smith ${ }^{1}$

${ }^{1}$ Consultant, ${ }^{3}$ Laboratory Haematology Registrar, Department of Laboratory Haematology, Austin Health, Melbourne, Australia

${ }^{2}$ Anaesthetic Resource Nurse, Department of Anaesthesia, Austin Health, Melbourne, Australia

${ }^{4}$ Head, Statistics and Decision Analysis Academic Platform, Florey Institute of Neuroscience \& Mental Health, Melbourne, Australia

${ }^{5}$ Adjunct Professor, School of Science, RMIT University, Melbourne, Australia

\section{Author's contributions}

Study design/planning: F.S.H., N.S., C.P., W.K.H., C.S.

Study conduct: F.S.H., N.S., C.P., F.N., A.M., A.W., W.K.H., C.S.

Data analysis: F.S.H., L.C., W.K.H.

Writing first draft: F.S.H., L.C.

Revising paper: all authors

Correspondence to:

Dr Frank Hong

Austin Pathology

PO Box 5555

Heidelberg, Victoria 3084

Australia

This is the author manuscript accepted for publication and has undergone full peer review but has not been through the copyediting, typesetting, pagination and proofreading process, which may lead to differences between this version and the Version of Record. Please cite this article as doi: 10.1111/imj.13613

This article is protected by copyright. All rights reserved. 
E-mail: frank.hong@austin.org.au

Ph: 0394965428

Word count of abstract: 241

Word count of main text: 1787

This article is protected by copyright. All rights reserved. 


\section{TYPE: ORIGINAL ARTICLE}

TITLE: (No more than 35 words)

Prevalence and causes of preoperative anaemia in elective major surgery patients

ABSTRACT: (Should be structured for Original Articles, as per below; no more than 250 words.)

Background: Preoperative anaemia is associated with increased morbidity and mortality in surgical patients. Recent national patient blood management guideline recommended screening surgical patients for anaemia and in particular iron deficiency anaemia, without reference to the prevalence of anaemia or iron deficiency anaemia in this patient population.

Aims: To establish the prevalence and cause of preoperative anaemia in elective major surgery patients.

Methods: Patients attending the anaesthetic pre-admission clinics from 1 July 2013 to 30 June 2014 prior to their major elective surgery in our institution were screened for anaemia and iron deficiency by measuring full blood count, iron studies and C-reactive protein. Patients who were anaemic were either further assessed in haematology clinic or had their medical records reviewed to ascertain the cause of the anaemia.

Results: Two hundred and eight (13.9\%) of 1494 patients were anaemic, with a male predominance (70.7\%). Fifty seven (27.4\%) of them had iron deficiency anaemia. Other common causes of anaemia include underlying malignancy (18.3\%), end stage renal failure (11.5\%) and other chronic diseases (7.2\%). In 53 patients (25.5\%), the cause was unknown. Anaemia was most commonly found in patients scheduled for gastrointestinal surgery.

Conclusion: Preoperative anaemia affects $13.9 \%$ of patients undergoing elective major surgery. The most common causes are iron deficiency and chronic diseases. The cause was unexplained in $25.5 \%$ of patients with anaemia. The prevalence of anaemia in different surgical specialties may have implications on the approach to screening, particularly in resource limited areas. 
KEYWORDS: (Five key words in order of importance for indexing purposes should be supplied below the abstract and should be taken from those recommended by the US National Library of Medicine's Medical Subject Headings (MeSH) browser list at http://www.n/m.nih.gov/J

Surgical procedures, anaemia, iron deficiency anaemia, prevalence

AUTHORS \& INSTITUTIONS: (Include any notes for Editorial Office information.) Corresponding Author information required ......

Authors' names: Frank S Hong ${ }^{1}$, Nicole Sieradzki ${ }^{2}$, Claire Pollock ${ }^{2}$, Faye Nasra ${ }^{2}$, Allison $\mathrm{Mo}^{3}$, Abbey Willcox ${ }^{3}$, Leonid Churilov ${ }^{4,5}$, Wai Khoon Ho ${ }^{1}$ and Carole Smith ${ }^{1}$

Authors' affiliation(s):

${ }^{1}$ Consultant, ${ }^{3}$ Laboratory Haematology Registrar, Department of Laboratory Haematology, Austin Health, Melbourne, Australia

${ }^{2}$ Anaesthetic Resource Nurse, Department of Anaesthesia, Austin Health, Melbourne, Australia ${ }^{4}$ Head, Statistics and Decision Analysis Academic Platform, Florey Institute of Neuroscience \& Mental Health, Melbourne, Australia

${ }^{5}$ Adjunct Professor, School of Science, RMIT University, Melbourne, Australia

Corresponding author full contact details:

Name: Frank Hong

Address: Level 6 Harold Stokes Building, Austin Health, 145 Studley Road

Post code: 3084

City: Heidelberg

Country: Australia

Fax:

Email: Frank.hong@austin.org.au

BACKGROUND: (Brief statement of relevant work or clinical situation, and hypothesis, if applicable.)

Preoperative anaemia is independently associated with increased morbidity and mortality in surgical patients. ${ }^{1-4}$ It is also a strong predictor of increased perioperative red blood cell transfusions..$^{5-6}$ Evidence is emerging that red blood cell transfusions may impact adversely on surgical patients, including higher mortality, ${ }^{7-11}$ increased risk of infection, ${ }^{7-9,12-13}$ and longer hospital and intensive care unit stays. ${ }^{7-8,14-15}$ 
Patient Blood Management guideline module 2: perioperative, ${ }^{16}$ released by National Blood Authority in Australia in 2011, recommended identifying preoperative anaemia and for surgical patients with, or at risk of, iron deficiency anaemia (IDA), to receive preoperative iron therapy. However, there was no reference to the prevalence of preoperative anaemia in surgical patients, particularly IDA.

The prevalence of preoperative anaemia reported in the literature is variable, partly related to use of different definitions and partly to the patient populations studied. Using The American College of Surgeons' National Surgical Quality Improvement Program database, Musallam et al found $30.4 \%$ of noncardiac surgery patients were anaemic, based on haematocrit. ${ }^{3}$ Similarly, Baron et al found a prevalence of $28.7 \% .{ }^{4}$ In other surgical populations, one study found $10.5 \%$ of major orthopaedic surgery patients to be anaemic, based on haemoglobin, with approximately one-third of the anaemia related to haematinic deficiency, iron deficiency (ID) being the most prevalent. ${ }^{17}$ This study also found a high prevalence of iron deficiency $(17.7 \%)$ in non-anaemic patients. In contrast, patients with colorectal cancer have a prevalence of $38 \%$ for IDA (haemoglobin <101g/L), ${ }^{18}$ and $60 \%$ for iron deficiency. ${ }^{19}$

Following the recommendations of the guideline, our institution established a multidisciplinary care pathway to screen for preoperative anaemia in patients undergoing major elective surgery. We sought to determine the prevalence of preoperative anaemia in this cohort of patients and the causes for anaemia, with a specific focus on iron deficiency.

METHODS: (Laboratory or other techniques used, including statistical analysis. Outcome measures clearly stated.) This audit was approved by the institution's human research ethics committee (Project number H2013/05052). 


\section{Preoperative haemoglobin optimisation pathway}

Elective surgery patients were screened for anaemia and ID. Anaemia was defined as haemoglobin $<130 \mathrm{~g} / \mathrm{L}$ for men, and $<115 \mathrm{~g} / \mathrm{L}$ for women, based on the reference ranges for haemoglobin in our pathology laboratory. A patient was considered to have ID if the ferritin was $<30 \mu \mathrm{g} / \mathrm{L}$. Full blood examination (FBE), iron studies and C-reactive protein (CRP) were ordered during surgical pre-admission clinics. CRP was used to assist with ferritin interpretation, as ferritin is an acute phase reactant, and can be elevated in the presence of inflammation. Patients who were having elective major surgery, such as cardiothoracic surgery, colorectal surgery, major joint replacements or vascular surgery, were further assessed by the anaesthetic team in the Anaesthetic Preadmission Clinics (APACs) prior to the operation. Patients who were found to have anaemia or ID were referred to the Haematology Clinic for further investigation to determine the cause(s) for anaemia and to commence treatment as required.

\section{Participants}

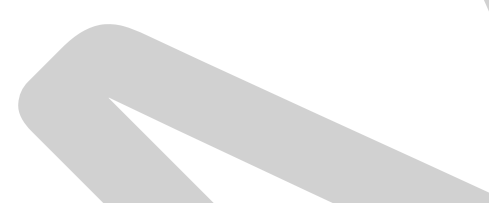

Patients aged 18 years or over who attended APAC during the period 1 July 2013 to 30 June 2014 and who were for elective major surgery were included. Basic patient demographic and laboratory data (FBE, iron studies and CRP) were collected.

Cause of anaemia was determined during assessment in Haematology clinic. For those anaemic patients who did not attend Haematology Clinic, the cause of anaemia was determined by reviewing the medical history and relevant blood test results, such as previous haemoglobin and creatinine. It was not possible to ascertain the cause in every patient due to the retrospective nature of the review.

\section{Statistical analysis}


Patient characteristics were summarized and reported as mean or medians (interquartile ranges) for continuous variables and as proportions for categorical variables.

RESULTS: (Statistically significant results and relevant negative data cited.)

\section{Patient Characteristics}

During the study period, 1494 patients attended APAC for elective major surgery (Table 1). All patients were screened for anaemia but 45 patients did not have iron studies performed. The median ferritin was $132 \mu \mathrm{g} / \mathrm{L}$ (IQR 70-227). Almost half of the patients were for orthopaedic surgery ( $n=662,44.3 \%)$, followed by cardiac surgery $(n=268,17.9 \%)$.

\section{Prevalence of Anaemia}

Two hundred and eight out of 1494 patients (13.9\%) were anaemic (Table 2). This included 147 men (17.9\% of all men) and 61 women (9.1\% of all women). The anaemia was not particularly marked for the majority of the patients: the median haemoglobin for men and women was $120 \mathrm{~g} / \mathrm{L}$ and $107 \mathrm{~g} / \mathrm{L}$, with the lowest haemoglobin at $76 \mathrm{~g} / \mathrm{L}$ and $88 \mathrm{~g} / \mathrm{L}$ respectively.

Gastrointestinal surgical units (upper gastrointestinal and colorectal) had the highest proportion of patients with anaemia, although the total number of patients is relatively small (154 patients). In contrast, the orthopaedic unit had the most number of patients with anaemia, but they only accounted for a small proportion of all patients undergoing orthopaedic surgery. 
IDA was present in $57 / 208$ patients ( $27.4 \%$ of those who are anaemic; $3.8 \%$ of total). These patients were spread across all surgical units (Table 2), with the urology unit having the least number by percentage (1.6\%), and colorectal unit having the highest proportion (12.5\%). Other common causes of anaemia were end stage renal failure (ESRF, 11.5\%), underlying malignancy (18.3\%) and chronic disease (7.2\%) (Table 4). Most patients with malignancy related anaemia were undergoing definitive surgery for that malignancy.

In 53 patients, the cause of the anaemia was not able to be determined. Most of these patients have relatively mild anaemia (median haemoglobin $122 \mathrm{~g} / \mathrm{L}$ and 106g/L for men and women respectively), with only 2 patients having haemoglobin $<100 \mathrm{~g} / \mathrm{L}$.

Iron deficient but not anaemic

Eighty-five patients (5.7\%) had absolute ID (ferritin $<30 \mu \mathrm{g} / \mathrm{L}$ ) without anaemia (Table 2). Again, the colorectal unit had the highest percentage, followed by orthopaedic and cardiac surgery units.

\section{DISCUSSION:}

Prevalence of anaemia in surgical patients has been variable in the literature, ranging from $5 \%$ in geriatric women with hip fractures to $75.8 \%$ in patients with advanced colorectal cancer, using various definitions of anaemia. ${ }^{20}$ In our cohort of elective major surgery patients, the overall prevalence was $13.9 \%$. More than one-third of these were due to chronic diseases, such as ESRF or malignancy. IDA accounted for $27.4 \%$, three quarters of which were new diagnoses. In just over a quarter of patients, the cause of anaemia was unknown. 
The prevalence of preoperative anaemia in elective major surgery patients appears to reflect that of the general population, as our results are similar to the World Health Organisation (WHO) estimate of $15 \%{ }^{21}$ and findings of The Third National Health and Nutrition Examination Survey in United States, which found increasing prevalence of anaemia after the age of 50 , with $11.0 \%$ of men and $10.2 \%$ of women 65 years and older being anaemic. ${ }^{22}$ Nutrient deficiency, anaemia of chronic disease and unexplained anaemia each accounted for approximately one-third of the causes. ${ }^{22}$ In contrast, a population study in Portugal found higher prevalence of anaemia (19.9\%), more prevalent among women, with $54.8 \%$ of anaemia due to ID. ${ }^{23} \mathrm{~A}$ number of other studies have reported varying prevalence of preoperative anaemia, but ID usually accounted for about one-third of the causes. ${ }^{17,22,24}$

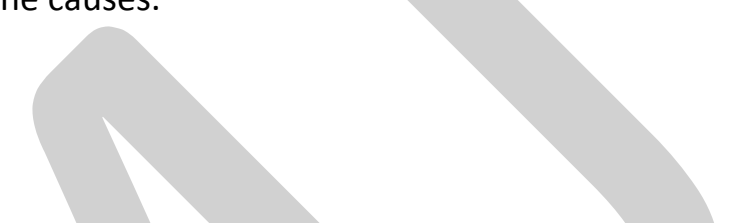

The patient population with the highest proportion of anaemia in our cohort was those scheduled to have gastrointestinal surgery, either upper or lower gastrointestinal tract. This is best explained by the reason for their surgery, which is often for malignancy. Gastrointestinal malignancy can lead to anaemia from bleeding (IDA) and/or through chronic disease/inflammation, two of the most common causes for preoperative anaemia. Eighteen out of the 40 patients with anaemia in upper gastrointestinal and colorectal surgical units have IDA.

Among the patients with IDA ( $n=57), 17$ patients were having surgery for the cause of the IDA resection of underlying gastrointestinal or bladder malignancy. This included 11 patients in colorectal surgery unit, 3 patients in upper gastrointestinal surgery unit and 3 patients in urology unit.

It is not surprising that chronic diseases accounted for more than one-third of anaemia, due to an ageing population and advances in healthcare, turning previously fatal illnesses into chronic diseases. Most of 
the patients who had malignancy-related anaemia were scheduled to have surgery for the underlying malignancy, which should help to improve the anaemia.

The cause of the anaemia for a sizeable number of patients could not be determined. This is partly due to limited information available in the medical records when reviewed, particularly if the patients were referred from another centre for a specific surgery (e.g. cardiac surgery), or where the anaemia was relatively mild in an otherwise asymptomatic patient (majority of these patients), a "watch-and-wait" approach was adopted and further invasive investigation, such as bone marrow biopsy, was not pursued for the time being. It is possible with further investigations, the cause of the anaemia in some of these patients can be established.

Our screening also identified a group of patients who were ID without anaemia. Together with the IDA group, they accounted for $9.5 \%$ of elective major surgery patients. Unsurprisingly, more colorectal surgery patients were ID (20.2\%), as most of them were undergoing surgery for gastrointestinal malignancy, which often causes ID with or without anaemia from bleeding. Other studies have also reported high rates of ID and IDA in colorectal surgery patients. ${ }^{18-19,25-26}$ In our cohort, cardiac surgery, thoracic surgery and orthopaedic units also had high prevalence of ID $(10.4 \%, 9.2 \%$ and $8.6 \%$ respectively). This may be related to the use of aspirin and other non-steroidal anti-inflammatory drugs in these groups of patient, which is a known risk factor for gastrointestinal bleeding. However, this will need to be confirmed with further study looking at the causes of iron deficiency in the elective major surgery patient population.

As the prevalence of ID and IDA are different across surgical units, this has implications for preoperative screening, especially if there is only limited resources available. 
While the prevalence of anaemia in our study is comparable to those published in the literature, it may be a slight underestimation, as our haemoglobin cut-off for anaemia in women is slightly lower than that of the WHO, which defines anaemia as haemoglobin below $120 \mathrm{~g} / \mathrm{L}$. However, this effect is likely to be small and not all published studies used the WHO cut-offs for anaemia.

The rate of ID in our study is based on ferritin $<30 \mu \mathrm{g} / \mathrm{L}$ (absolute ID). This may have underestimated the true prevalence of ID since ferritin is an acute phase reactant and is raised at times of inflammation, as reflected by CRP. It is possible some of the patients with low normal ferritin (30-100 $\mathrm{\mu g} / \mathrm{L})$ and CRP >10 $\mathrm{mg} / \mathrm{L}$ may actually be iron deficient.

The standard iron study measures serum iron, serum transferrin, transferrin saturation and serum ferritin, none of which is a good marker for ID in the setting of concurrent inflammation. It has been proposed that when ferritin is $>100 \mu \mathrm{g} / \mathrm{L}$ in the setting of inflammation, true iron deficiency is unlikely, ${ }^{27}$ however this requires further validation. Other tests that may help are soluble transferrin receptor and hepcidin. The former is elevated in ID and low-normal in chronic inflammation, but is not a routine test in our diagnostic laboratory, hence no results were available. Hepcidin is low in ID and high in chronic inflammation, but has mainly been used in the research setting.

Although this is a single centre study, our institution serves a catchment area of more than 1.2 million people across eight local government areas, giving some confidence that the results are likely to reflect that of the overall elective major surgery patient population. 
CONCLUSION: (Referable to the aims of the study and may include suggestions for future action.)

The overall prevalence of preoperative anaemia in elective major surgery patients is $13.9 \%$, similar to that of the general population, with variations between surgical units. The main reversible cause of anaemia is iron deficiency, which is most common in patients scheduled for gastrointestinal surgery. These data will assist in the design of future preoperative anaemia screening and intervention programs. 
REFERENCES: (Supply a maximum of 60 references. Style and punctuation should conform to the Vancouver format. List all authors when six or fewer; when seven or more list the first six and add et al. The issue number should not be quoted. Website references - treat as other reference. In the text, references should be cited using superscript Arabic numerals in the order in which they appear. If cited only in tables or figure legends number them according to the first identifications of the table or figure in the text. In the reference list, the references should be numbered and listed in order of appearance in the text.)

1. Karkouti K, Wijeysundera DN, Beattie WS, and the Reducing Bleeding in Cardiac Surgery (RBC) Investigators. Risk associated with preoperative anemia in cardiac surgery: a multicentre cohort study. Circulation 2008; 117: 478-84.

2. Van Straten AH, Hamad MA, van Zundert AJ, Martens EJ, Schonberger JP, de Wolf AM. Preoperative haemoglobin level as a predictor of survival after coronary artery bypass grafting: a comparison with the matched general population. Circulation 2009; 120: 118-25.

3. Musallam KM, Tamim HM, Richards T, Spahn DR, Rosendaal FR, Habbal A, et al. Preoperative anaemia and postoperative outcomes in non-cardiac surgery: a retrospective cohort study. Lancet 2011; 378: 1396-407.

4. Baron DM, Hochrieser H, Posch M, Metnitz B, Rhodes A, Moreno RP, et al. Preoperative anaemia is associated with poor clinical outcome in non-cardiac surgery patients. Br J Anaesth 2014; 113: 416-23.

5. Kotzé A, Carter LA, Scally AJ. Effect of a patient blood management programme on preoperative anaemia, transfusion rate, and outcome after primary hip or knee arthroplasty: a quality improvement cycle. Br J Anaesth 2012; 108: 943-52.

6. Faris PM, Spence RK, Larholt KM, Sampson AR, Frei D. The predictive power of baseline haemoglobin for transfusion risk in surgery patients. Orthopedics 1999; 22: s135-40.

7. Dunne JR, Malone D, Tracy JK, Gannon C, Napolitano LM. Perioperative anemia: an independent risk factor for infection, mortality, and resource utilization in surgery. J Surg Res 2002; 102: 23744.

8. Murphy GJ, Reeves BC, Rogers CA, Rizvi SI, Culliford L, Angelini GD. Increased mortality, postoperative morbidity, and cost after red blood cell transfusion in patients having cardiac surgery. Circulation 2007; 116: 2544-52.

9. Bernard AC, Davenport DL, Chang PK, Vaughan TB, Zwischenberger JB. Intraoperative transfusion of $1 \mathrm{U}$ to $2 \mathrm{U}$ packed red blood cells is associated with increased 30-day mortality, surgical-site infection, pneumonia, and sepsis in general surgery patients. J Am Coll Surg 2009; 208: 931-7.

10. Bursi F, Barbieri A, Politi L, Di Girolamo A, Malagoli A, Grimaldi T, et al. Perioperative red blood cell transfusion and outcome in stable patients after elective major vascular surgery. Eur J Vas Endovas Surg 2009; 37: 311-8. 
11. Ferraris VA, Davenport DL, Saha SP, Austin PC, Zwischenberger JB. Surgical outcomes and transfusion of minimal amounts of blood in the operating room. Arch Surg 2012; 147:49-55.

12. Chang H, Hall GA, Geerts WH, Greenwood C, McLeod RS, Sher GD. Allogeneic red blood cell transfusion is an independent risk factor for the development of postoperative bacterial infection. Vox Sang 2000; 78: 13-8.

13. García-Alvarez F, Al-Ghanem R, García-Alvarez I, López-Baisson A, Bernal M. Risk factors for postoperative infections in patients with hip fracture treated by means of Thompson arthroplasty. Arch Gerontol Geriatr 2010; 50: 51-5.

14. Weber EWG, Slappendel R, Prins MH, Van Der Schaaf DB, Durieux ME, Strümper D. Perioperative blood transfusions and delayed wound healing after hip replacement surgery: effects on duration of hospitalization. Anesth Analg 2005; 100: 1416-21.

15. BuSaba NY, Schaumberg DA. Predictors of prolonged length of stay after major elective head and neck surgery. Laryngoscope 2007; 117: 1756-63.

16. National Blood Authority. Patient Blood Management guideline: Module 2 - Peri-operative. Canberra: 2012.

17. Bisbe E, Castillo J, Sáez M, Santiveri X, Ruíz A, Muñoz M. Prevalence of preoperative anemia and hematinic deficiencies in patients scheduled for elective major orthopaedic surgery. Transfus Alternat Transfus Med 2008; 10: 166-73.

18. Acher PL, Al-Mishlab T, Rahman M, Bates T. Iron-deficiency anaemia and delay in the diagnosis of colorectal cancer. Colorectal Dis 2003; 5: 145-8.

19. Beale AL, Penney MD, Allison MC. The prevalence of iron deficiency among patients presenting with colorectal cancer. Colorectal Dis 2005; 7:398-402.

20. Shander A, Knight K, Thurer R, Adamson J, Spence R. Prevalence and outcomes of anemia in surgery: a systematic review of the literature. Am J Med 2004; 116: 58S-69S.

21. World Health Organisation. Worldwide Prevalence of Anemia 1993-2005. Geneva, Switzerland: 2008.

22. Guralnik JM, Eisenstaedt RS, Ferrucci L, Klein HG, Woodman RC. Prevalence of anemia in persons 65 years and older in the United States: evidence for a high rate of unexplained anemia. Blood 2004; 104: 2263-8.

23. Fonseca C, Marques F, Robalo Nunes A, Belo A, Brilhante D, Cortez J. Prevalence of anaemia and iron deficiency in Portugal: the EMPIRE study. Int Med J 2016; 46: 470-8.

24. Saleh E, McClelland DBL, Hay A, Semple D, Walsh TS. Prevalence of anaemia before major joint arthroplasty and the potential impact of preoperative investigation and correction on perioperative blood transfusions. Br J Anaesth 2007; 99: 801-8. 
25. Sadahiro S, Suzuki T, Tokunaga N, et al. Anaemia in patients with colorectal cancer. J Gastroenterol 1998; 33: 488-494.

26. Ho $\mathrm{CH}, \mathrm{Yu}$ YB, $\mathrm{Wu} \mathrm{PH}$. The prevalence of iron deficiency anaemia and its clinical implications in patients with colorectal carcinoma. J Chin Med Assoc 2008; 71: 119-122.

27. Weiss G, Goodnough LT. Anemia of chronic disease. N Engl J Med 2005; 352: 1011-23. 
Table 1. Patient characteristics. Values are median (range) or number (proportion).

\begin{tabular}{lc}
\hline Male:Female & $822(55.02 \%): 672(44.98 \%)$ \\
Age (years) & $65.2(18-92)$ \\
Haemoglobin $(g / L)$ & $144(76-186)$ \\
Male & $120(76-129)$ \\
Hb <130g/L $(n=147)$ & $135(88-171)$ \\
Female & $107(88-114)$ \\
$H b<115 g / L(n=61)$ & $132(5-3450)$ \\
\hline Ferritin $+(\mu g / L)$ &
\end{tabular}

†45 patients did not have ferritin levels taken 
Table 2. Prevalence of anaemia, iron deficiency anaemia and iron deficiency without anaemia by surgical units. Values are number.

\begin{tabular}{|c|c|c|c|c|c|c|c|c|c|c|}
\hline \multirow{2}{*}{ Surgical unit } & \multirow{2}{*}{$\begin{array}{l}\text { Number }(\%)^{*} \text { by } \\
\text { surgical unit }\end{array}$} & \multicolumn{3}{|c|}{ Anaemia } & \multicolumn{4}{|c|}{ Iron deficiency anaemia } & \multicolumn{2}{|c|}{$\begin{array}{c}\text { Iron deficiency } \\
\text { without anaemia }\end{array}$} \\
\hline & & Male & Female & Number & $\begin{array}{c}\% \text { of } \\
\text { surgical } \\
\text { unit }\end{array}$ & Number & $\begin{array}{c}\% \text { of } \\
\text { surgical } \\
\text { unit }\end{array}$ & $\begin{array}{c}\% \text { of } \\
\text { anaemic } \\
\text { patients }\end{array}$ & Number & $\begin{array}{c}\% \text { of } \\
\text { surgical } \\
\text { unit }\end{array}$ \\
\hline Orthopaedic & $662(44.3 \%)$ & 45 & 23 & 68 & $10.3 \%$ & 14 & $2.1 \%$ & $20.6 \%$ & 43 & $6.5 \%$ \\
\hline Cardiac & 268 (17.9\%) & 23 & 12 & 35 & $13.1 \%$ & 11 & $4.1 \%$ & $31.4 \%$ & 17 & $6.3 \%$ \\
\hline Urology & $126(8.4 \%)$ & 12 & 2 & 14 & $11.1 \%$ & 2 & $1.6 \%$ & $14.3 \%$ & 4 & $3.2 \%$ \\
\hline Thoracic & $109(7.3 \%)$ & 9 & 2 & 21 & $19.3 \%$ & 4 & $3.7 \%$ & $19.0 \%$ & 6 & $5.5 \%$ \\
\hline Colorectal & $104(7.0 \%)$ & 10 & 11 & 27 & $26.0 \%$ & 13 & $12.5 \%$ & $48.1 \%$ & 8 & $7.7 \%$ \\
\hline Vascular & $75(5.0 \%)$ & 13 & 0 & 13 & $17.3 \%$ & 4 & $5.3 \%$ & $30.8 \%$ & 1 & $1.3 \%$ \\
\hline Hepatobiliary & $68(4.6 \%)$ & 6 & 4 & 10 & $14.7 \%$ & 2 & $2.9 \%$ & $20.0 \%$ & 4 & $5.9 \%$ \\
\hline Upper gastrointestinal & $50(3.3 \%)$ & 8 & 5 & 13 & $26.0 \%$ & 5 & $10.0 \%$ & $38.5 \%$ & 1 & $2.0 \%$ \\
\hline Ear, Nose and Throat & $23(1.5 \%)$ & 5 & 1 & 6 & $26.1 \%$ & 2 & $8.7 \%$ & $33.3 \%$ & 1 & $4.3 \%$ \\
\hline \multirow[t]{2}{*}{ Breast } & 9 (0.9\%) & & 1 & 1 & $11.1 \%$ & 0 & 0 & 0 & 0 & 0 \\
\hline & 1494 & 147 & 61 & 208 & $13.9 \% *$ & 57 & $3.8 \% *$ & $27.4 \%$ & 85 & $5.7 \% *$ \\
\hline
\end{tabular}


*As a proportion $(\%)$ of the entire surgical cohort $(n=1494)$
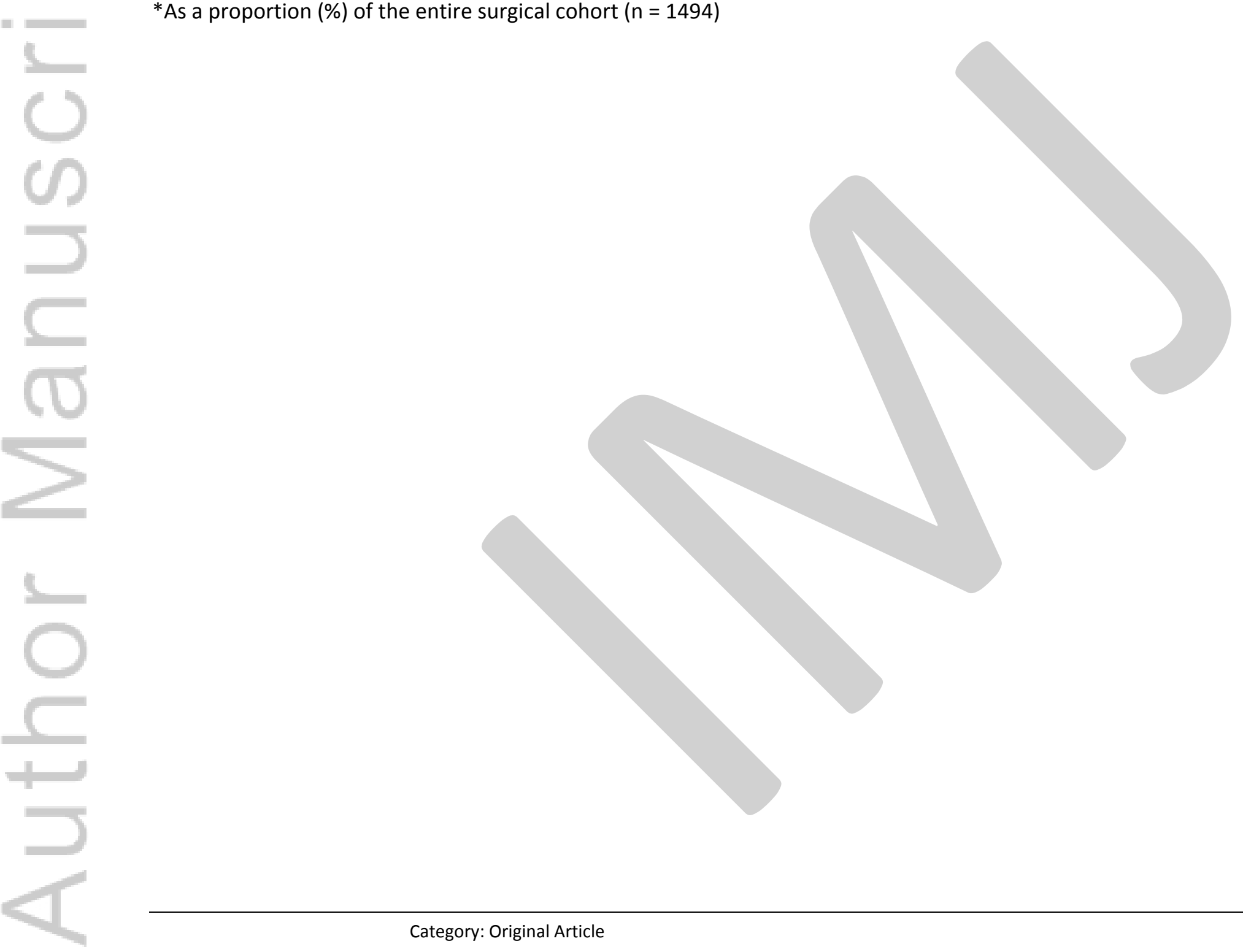
This article is protected by copyright. All rights reserved. 
Table 3. Causes of anaemia. Values in number (proportion).

\begin{tabular}{lc}
\hline Iron deficiency & $43(20.7 \%)$ \\
Treated iron deficiency & $14(6.7 \%)$ \\
Malignancy \pm chemotherapy & $38(18.3 \%)$ \\
End stage renal failure & $24(11.5 \%)$ \\
Other chronic diseases & $15(7.2 \%)$ \\
Thalassaemia & $8(3.8 \%)$ \\
Non-malignancy related bleeding & $4(1.9 \%)$ \\
Blood loss from surgery within preceding 3 months & $4(1.9 \%)$ \\
B12 deficiency & $2(1.0 \%)$ \\
Recent hospitalisation for medical illness & $1(0.5 \%)$ \\
Folate deficiency & $1(0.5 \%)$ \\
Autoimmune haemolytic anaemia & $1(0.5 \%)$ \\
\hline Could not be determined & $53(25.5 \%)$ \\
\hline
\end{tabular}




\section{University Library}

\section{- M M N E R VA A gateway to Melbourne's research publications}

Minerva Access is the Institutional Repository of The University of Melbourne

Author/s:

Hong, FS;Sieradzki, N;Pollock, C;Nasra, F;Mo, A;Willcox, A;Churilov, L;Ho, WK;Smith, C

Title:

Prevalence and causes of preoperative anaemia in elective major surgery patients

Date:

2017-12-01

Citation:

Hong, F. S., Sieradzki, N., Pollock, C., Nasra, F., Mo, A., Willcox, A., Churilov, L., Ho, W. K. \& Smith, C. (2017). Prevalence and causes of preoperative anaemia in elective major surgery patients. INTERNAL MEDICINE JOURNAL, 47 (12), pp.1400-1404. https://doi.org/10.1111/ imj. 13613.

Persistent Link:

http://hdl.handle.net/11343/293973 